\title{
Comparison of the Value of Teaching and Learning
}

\author{
George Drops \\ National University, United States
}

\begin{abstract}
Though colleges and universities are often identified as teaching institutions, learning is the goal of all education. Just as teaching is done in different ways so also learning occurs through various practices. Ranking the importance of various learning activities provides a way for comparing value from the perspective of both teachers and students.
\end{abstract}

\section{Introduction}

Directing and helping students to learn can be done in a number of ways of which the following are likely to be commonly used to engage students more directly in their learning.

\section{Teaching strategies}

Covering content is an all too common approach to teaching especially when using course textbooks. Maryellen Weimar has clearly stated that "we "use' content (not cover it) as a vehicle to develop learning skills" to "help students acquire a repertoire of strategies, approaches, and techniques" to be used in a specific discipline...to promote self-awareness of learning ... and develop confidence in their ability to learn" [5].

Asking questions about a subject when presenting particular topics in class is another common approach used by teachers to stimulate learning. McKeachie points out that "study questions intended to guide the students' reading are often helpful." $\mathrm{He}$ further points out that different types of questions can lead to better learning. Such include higher-level questions which "increase the effectiveness of student processing of the reading." [4].

A very relevant and focused way to increase student learning is by asking them questions directly related to the course learning outcomes in contrast to questions about the course content. Asking students if they are able or have already achieved a specific learning outcome is one way to focus learning on specific ideas. Another way is to ask students how they plan to use knowledge about a particular subject in their work, relationships or research.
Besides starting a discussion by asking questions, McKeachie emphasizes a number of specific ways for stimulating discussions including sharing a common experience, dealing with a controversy, analyzing a case or problem, and developing a Socratic dialogue. The more relevant topics are for such discussions, the more likely students are to be actively engaged in sharing their ideas and individual experiences.

\section{Group learning}

Establishing learning groups is more likely to lead to better understanding of specific topics resulting in more personal and deeper learning since such discussions require students to present ideas in their own words often related to their own experience relevant to the topic. Discussions are usually specific to a particular subject and almost always personal based upon practical experience. McKeachie states that "one of the best ways of starting a discussion is to refer to a concrete, common experience through presentation of a demonstration, film, role play, short skit, or brief reading." [4]. Among the most common experiences for learners today are to search the internet for ideas and information and to share what they have discovered with friends using social media.

A way to extend learning through discussion groups is to have students identify and measure the activity of each member in each group. Various roles can be identified such as group leader, dominator, questioner and presenter enabling each group member to recognize and understand their role throughout the discussion. Having an outside viewer draw a design that captures the direction of the discussion based upon seat location and number of comments directed to specific others in the group is an excellent approach to helping students appreciate the value of discussion and assess their performance in the discussion based on real and timely data.

Such an approach not only gives students a relevant image of how participation occurred in the discussion but also how they interacted with other 
members in either supporting their ideas or challenging the information presented.

\section{Practical learning}

A follow-up practice to such learning is to have representatives from each group describe how the group managed the discussion, what was learned and what ideas were most valuable, and what they might do when engaged in another discussion in the course. Often an analysis of one's performance with feedback from others leads to better learning beyond just understanding the meaning of a particular concept or subject.

Another common approach based on group discussions is to have one member from each group present a summary of their discussion identifying what conclusions were reached and what learning occurred. Such a practice also provides the opportunity for each individual speaker to record their presentation on their cell phone so that they can review and reflect on their learning as well as share their learning experience with family and friends.

Besides creating such a video, other ways to further learning are to relate the ideas presented to relevant concepts in the textbook, to develop one or two multiple choice questions as preparation for exams, to search the internet for more information about the ideas shared in the class discussions, and to write a short paper on both the knowledge acquired in the discussion as well as the learning that came from one's participation in that discussion.

Knowing everything presented in a textbook as a way for preparing to take multiple choice tests is a common way of learning at nearly every level of education. Engaging students more actively in the learning process and enabling them to review their performance by writing a paper on that experience are exercises more likely to lead to a deeper level of learning much more personal and of greater value to each participant in that process.

It has been stated that "It is the one who does the work who does the learning." [2]. Education is experiencing a great shift these days based upon focusing more on learning than on teaching. People can learn without being taught just by observing what happens. What people do with the knowledge acquired in a learning process becomes more valuable and worthwhile in contrast to just acquiring but never using such knowledge beyond answering multiple choice test questions. Using knowledge is of greater value than acquiring knowledge just as experience is of more value than collecting knowledge.

Two questions teachers can ask themselves when preparing to teach a class are the following: What do
I want to teach focusing on what the teacher does in the class? And what do I want my students to learn focusing on what the students do in the class?

\section{Experiential learning}

Beyond these two questions lies an equally valuable question to consider: What is the best way for students to learn? How would you rank in order of importance the following ways students learn best?

Recognizing the key ideas found in the textbook.

Remembering the key points presented in the instructor's lectures.

Explaining key concepts in one's own words.

Answering the instructor's questions on course topics.

Correctly answering multiple choice test questions.

Solving problems related to ideas and concepts presented in class.

Thinking critically and/or creatively about the subject being studied.

Conducting research on specific problems, issues, ideas, etc.

Writing papers analyzing and evaluating issues, problems, case studies, etc.

Discussing course topics with other students individually or in groups.

Applying ideas presented in class to one's professional and/or personal life.

Compare your ranking with the rankings of your students - a learning experience for everyone.

The same survey was completed by both men and women adult learners and new and experienced adjunct faculty. The results of these surveys on teaching and learning are listed below.

\section{Best ways of learning}

In a study of teaching and learning, students and instructors were asked to rank the items listed above regarding ways students learn best. Thirty-six men and thirty-nine women, all of whom were adult learners, completed this survey. The results of their rankings are as follows:

\section{Rankings of Male Learners}

1. Thinking Critically/Creatively

2. Applying Ideas to Life

3. Explaining Concepts in Own Words 
4. Solving Related Problems

5. Recognizing Textbook Key Ideas

6. Conducting Research on Issues

7. Remembering Lecture Ideas

8. Answering Instructor's Questions

9. Group Discussing Topics

10. Writing Analytical Papers

11. Answering Multiple Choice Questions

\section{Rankings of Female Learners}

1. Thinking Critically/Creatively

2. Applying Ideas to Life

3. Explaining Concepts in Own Words

4. Solving Related Problems

5. Remembering Lecture Ideas

6. Recognizing Textbook Key Ideas

7. Answering Instructor's Questions

8. Conducting Research on Issues

9. Group Discussing Topics

10. Writing Analytical Papers

11. Answering Multiple Choice Questions

\section{Rankings of Faculty Instructors}

The same survey was completed by both men and women adjunct faculty teaching at the university. The results of their rankings are as follows:

\section{Rankings of New Faculty}

1. Thinking Critically/Creatively

2. Applying Ideas to Life

3. Solving Related Problems

4. Explaining Concepts in Own Words

5. Group Discussing Topics

6. Conducting Research on Issues

7. Writing Analytical Papers

8. Recognizing Textbook Key Ideas

9. Remembering Lecture Ideas

10. Answering Instructor's Questions

11. Answering Multiple Choice Questions

\section{Rankings of Experienced Faculty}

1. Thinking Critically/Creatively

2. Applying Ideas to Life

3. Solving Related Problems

4. Conducting Research on Issues

5. Explaining Concepts in Own Words

6. Group Discussing Topics

7. Writing Analytical Papers

8. Recognizing Textbook Key Ideas

9. Remembering Lecture Ideas

10. Answering Instructor's Questions

11. Answering Multiple Choice Questions

\subsection{Analysis of the rankings}

The highest rated items reinforce the idea of personalized learning indicating that students want to learn ideas that are practical and relevant to their life situation. This is in contrast to their lowest rated items which are more focused on textbook knowledge with less relevance to real life experience.

It is interesting from my own teaching experience that the majority of students identify the best learning experience they had in my classes was learning how to work on teams, especially on virtual teams.

Learning that comes from team work shared in discussion among team members has more relevance to students when the topics are focused on student's experience. In contrast to a class of twenty students which has one teacher and twenty-one learners, a team of five students has five learners and five teachers.

This may be especially true for adult learners who have workplace experience in various types of organizations. Such learning is mostly informal as shared in conversations in contrast to the formal types of learning in traditional classrooms. Quinn writes that "the 70:20:10 framework...reflects workers' beliefs that only 10 percent of workplace knowledge comes from training, 20 percent comes from coaching and mentoring, and 70 percent comes from learning on the job." (5). Training, the closest practice focused on learning in the workplace compared to learning in colleges and universities is considered more as an event rather than a learning experience. Consequently individuals are more engaged in learning when such a practice is more directly related to specific experience in contrast to impersonal textbook knowledge or faculty lectures.

This is reinforced by experience when I have students develop their own multiple choice questions and sharing these questions in their group to decide which questions to use on tests. While not every student in the class may get the right answers to multiple choice test questions developed by their classmates, the best learning is more likely to come from the work and discussions of students in developing those questions. Developing test questions may be a better way of learning than listening to instructors lecture on key ideas since the former more actively engages students in the learning process. This fact is supported by the following rankings on teaching. 


\section{The art and science of teaching}

Teaching is a vocation, a calling to a specific practice. Seven different descriptions of teaching are listed in dictionaries. Perhaps the most common description, lecturing, is often identified with college and university teaching even though the word originally referred to reading. Teaching is also identified as an art and science. It is uncertain whether teachers identify themselves as either artists or scientists though they might use skills common to both.

Teaching is a profession requiring knowledge, skills and abilities that differ depending upon the level of students in classes taught. This may be most relevant to professors teaching in universities and important to many teachers at every level of education. "As members of a teaching/learning community individuals are not only expected to practice an art or science, but also act as a 'professor' of knowledge." [3]. Though classroom teachers are specifically taught to teach particular subjects, everyone including both teachers and students teach others whether they realize it or not. Consequently we are both teachers and learners though the experience happens at different times and is different for each person. In preparing to teach, faculty need to focus more on student's learning than on their teaching. In other words, when preparing to teaching faculty need to move from identifying what they want to teach to identifying what they want their students to learn and what is the best way for them to learn that.

\section{Learning to teach}

Teachers are continuously learning how to teach more effectively, depending upon both their students as well as their subjects. Many individuals learned to teach through social learning, originally described as learning by observing others teaching when they were students in their classroom. Teachers continue to learn how to teach more commonly through a different and contemporary form of social learning which occurs when teachers get together and share their experiences, ideas and question about both teaching and learning. Teachers sometimes have role models - teachers they had in class as students who impressed them with their teaching. Students seldom have other students as role models.

"Fortunately, most human behavior is learned observationally through modeling: from observing others one forms an idea of how new behaviors are performed, and on later occasions this coded information serves as a guide for action" [1].
Teaching often related to training has been described as "telling" though the two are very different in many ways such as subjects, situations, objectives, etc. Teaching has also been described as an art with a different canvas. Referring to the writing of Garrett and Holmes, Peter Jarvis stated that "As members of a teaching/learning community individuals are not only expected to practice an art or science, but also act as a "professor' of knowledge" [3].

While teachers differ in their artistic approach to teaching, many teachers are now focused on the science of teaching particularly related to the use of technology in and out of the classroom. In such situations it is not uncommon for teachers and students to reverse roles with the latter teaching the former how and what to learn. Though it is common to hear from teachers that they love teaching, it is not as common to hear from students that they love learning.

\section{Assessing teaching}

To continue your learning, rank in order of importance what teaching means to you?

- Covering the content of the course.

- Explaining ideas in the textbook.

- Sharing experiences on practical applications related to the course content.

- Questioning students on their knowledge and thinking about the course subjects.

- Helping students achieve the course learning outcomes.

- Designing learning activities that engage the students.

- Developing group or team projects for students to complete and present.

- Having students summarize textbook chapters or research current relevant issues.

- Constructing test questions on the key ideas presented in the course.

Once again, compare your rankings to those of your students. The two exercises are likely to lead to lively discussions of value to both teachers and students, all of whom are learning and teaching. While there are no right or wrong answers, the information collected provides a good perspective of how value is determined in relation to student learning as considered by both faculty and students. Hopefully, this will encourage faculty to reconsider their approach to teaching by developing a more learner-centered strategy. 


\section{Best ways of teaching}

\section{Rankings of Male Adult Learners}

1. Sharing Practical Experience

2. Explaining Textbook Ideas

3. Achieving Learning Outcomes

4. Designing Learning Activities

5. Covering Content

6. Questioning Student Knowledge

7. Constructing Test Questions

8. Developing Group Projects

9. Students Summarize Chapters

\section{Rankings of Female Adult Learners}

1. Sharing Practical Experience

2. Designing Learning Activities

3. Achieving Learning Outcomes

4. Covering Content

5. Explaining Textbook Ideas

6. Questioning Student Knowledge

7. Constructing Test Questions

8. Students Summarize Chapters

9. Developing Group Projects

\section{Rankings of Faculty Instructors}

The same survey was completed by both men and women adjunct faculty teaching at the university. The results of their rankings are as follows:

\section{Rankings of New Faculty}

1. Thinking Critically/Creatively

2. Applying Ideas to Life

3. Solving Related Problems

4. Explaining Concepts in Own Words

5. Group Discussing Topics

6. Conducting Research on Issues

7. Writing Analytical Papers

8. Recognizing Textbook Key Ideas

9. Remembering Lecture Ideas

10. Answering Instructor's Questions

11. Answering Multiple Choice Questions

\section{Rankings of Experienced Faculty}

1. Thinking Critically/Creatively

2. Applying Ideas to Life

3. Solving Related Problems

4. Conducting Research on Issues

5. Explaining Concepts in Own Words

6. Group Discussing Topics

7. Writing Analytical Papers

8. Recognizing Textbook Key Ideas
9. Remembering Lecture Ideas

10. Answering Instructor's Questions

11. Answering Multiple Choice Questions

\section{Analysis of the rankings}

\subsection{Sharing practical experiences}

While student rankings identify the idea of sharing practical experiences may be directly related to an instructor's teaching, sharing their own experience based on the teacher's identification of the type of experiences for learning can be significant. A good example for teaching students about talent, a key factor in most companies and organizations these days, is to have students share their ideas about talented individuals.

The assignment $\mathrm{I}$ give to students in class discussions is to identify job interview questions they have been asked by company individuals when applying for employment in that company. In identifying these questions, I also have students share their ideas on what they think the interviewer was looking for in asking those particular questions. I also have students who have interviewed candidates for jobs in their company to identify questions they have asked them in the interview and what they were looking for in asking such questions.

The learning and experience students get from reading and discussing the ideas presented in those exercises provide the kind of information that is not likely to be found in textbooks but is based on experiences common to most individuals seeking employment.

\subsection{Explaining textbook ideas and covering content}

A common teaching strategy to increase student learning is to have individual students summarize the key ideas based on specific information contained in the textbook. This practice provides students with the learning experience of being similar to a teacher. The same is true when students are presenting the ideas they developed in their research papers. Both assignments actively engage these students in their learning while providing their classmates with a different way of reviewing key ideas in the course. Fundamental to both of these concepts is the reality that learning is personal - each individual student learns in a personal way especially when they are sharing their ideas and experience in researching and developing those ideas. 


\subsection{Achieving learning outcomes}

Most courses already have identified the specific learning outcomes students are expected to achieve in the class. Of more relevance, especially to adult learners, is the need for students to identify specific areas of relevance to their responsibilities in the workplace. In education, the focus is on acquiring knowledge to be able to earn a passing grade for each course. In the workplace, the value of educational learning is directly related to job performance improvement based on the knowledge acquired in the classroom. The difference is significant and needs to be appreciated by all learners, students and teachers.

\subsection{Questioning Student Knowledge}

A common practice of teachers is to ask questions of students related to specific ideas in the course based either on instructor lectures or required reading by students. The critical factor for instructors is not just developing meaningful questions but also waiting a sufficient time for students to think about the answer they would give.

Teachers need to wait long enough for students to identify their answer and decide how they will present that answer to the entire class. This is likely to involve more than a few seconds of waiting time by the instructor for the students to provide a meaningful answer to the question.

\subsection{Constructing Test Questions}

As indicated earlier, this is a responsibility of the teacher though it can also be assigned to students as a way of preparing them for multiple choice tests. Developing such test questions identifies which ideas were of most value in the course as well as in the textbook. This process also supports students in preparing for the tests faculty develop for measuring student learning and acquisition of knowledge. Such an assignment can be done individual or in groups as determined by the instructor, both of which add value to student learning.

\subsection{Developing Group Projects}

Despite student reluctance and resistance to working in groups and developing research papers, this is a common way that much work is accomplished in the workplace. It is also a good way for students to learn different roles for working in a group or on a team. An excellent way to improve the learning process of groups is to have them diagram the interactions of group members in discussing their ideas and responsibilities related to the group project. This identifies who contributed what to the discussion. It also helps students understand what roles they play in working on a group and what ideas they bring to the assignment.

Often the individual group members take responsibility for delivering in their class presentation the ideas they provided to the group in their discussion of the assignment.

Group or team learning has been commonly used in classrooms for years. With the development of online classes, group and team learning requires new skills beyond just presenting ideas discussed in one's group. Before the development of online technology, a common concern of group member when discussing their assignment was to identify who had the artistic ability to graphically design the key ideas that would be delivered in the group's presentation to their class.

Internet technology now has the resources needed to use graphic images identified with the key concepts and relationships developed in the research and writing of the students' paper. While students are accustomed to writing research papers using the guidelines and requirements of the academy, they are less likely to be as knowledgeable and skillful in developing graphic illustration of key concepts used in their papers and presentation, especially in the latter.

The development of online technology enables presenters to deliver specific ideas using design and illustrations that give a picture of the overall concept as well as visual identification of specific components of that concept. While design is a good way of identifying key concepts, an explanation is also needed to clarify the specific focus and relationship of the ideas to one another as well as the sequence in the development and use of these concepts.

Such designs are also more common and relevant to the ways information and ideas are presented on the Internet in contrast to the traditional ways of writing research papers. A visual component of concepts and ideas has added value beyond the listing and description of information and ideas as commonly presented in written documents. While words can be used to describe ideas and information, visual images add value that often provides a new dimension to student learning.

\section{References}

[1] Bandura, Albert. Social Learning Theory. General Learning Press. New York. 1977. 
[2] Doyle, T. Learner-Centered Teaching: Putting the Research on Learning Into Practice. Stylus Publishing. Sterling, Virginia, 2011, p.

[3] Jarvis, P. (Editor). The Theory \& Practice of Teaching. Kogan Page. London, UK 2002

[4] McKeachie, WJ. and M. Svinicki. McKeachie's Teaching Tips: Strategies, Research, and Theory for College and University Teachers. Thirteenth Edition. Wadsworth, Cengage Learning. Belmont, California. 2011,

[5] Quinn, Clark N. Revolutionize Learning \& Development: Performance and Innovation Strategy for the Information Age. Wiley. San Francisco 2014.

[6] Weimer, M.E., Learner-Centered Teaching: Five Key Changes to Practice. Jossey-Bass. San Francisco, California 2002. 